\title{
PAEDIATRICS IN ARMY GENERAL PRACTICE
}

\author{
Lieutenant-Colonel S. E. M. JARVIS \\ M.B., Ch.B., M.R.C.P., D.C.H.
}

Adviser in Paediatrics, Cambridge Military Hospital, Aldershot.

THERE is considerable scope for paediatrics in the Army since children, unlike the selected soldier, get all the diseases their civilian counterparts do, and a few which are regional due to their overseas stay. More than half the Army general practitioner's clientele are children, and he has to deal not only with the ailing child, but the parents as well. He should listen carefully to the mother's story--it is after all her child-and sune is relating what worries her abcut the child. If a parent seems to be rather aggressive, it is usually due to anxiety and so try to be kind always and remember you are there to help if possible, not to sit in judgement, even if you feel the parents are rathèr stupid. Remember too, that hospital is the second best place for the sick child-nome is best-but many children have to be admitted because they are very ill or the home conditions are not satisfactory.

As the Army has accepted accompanied postings overseas, there are a large number of children in overseas stations. For example in the Army alone in B.A.O.R. there are 50,000 soldiers and 16,500 children and in F.A.R.E.L.F. 31,500 soldiers and 11,500 children approximately. So you will see the size of the commitment and if you include for example in Singapore, Gurkhas whom we look after by right; and Malayans, by courtesy, plus the children of teachers, NAAFI, Command Secretariat and other quasi-military personnel, these numbers increase considerably. There are also a number of handicapped children, both physical and mental who require special attention and facilities.

There are several important differences between the service family and its civilian counterpart. They are posted overseas, where they are deprived of the succour and support of relatives when in adversity. The father may be away from the family on duty for long periods. To attend a hospital may involve a long journey and transport cannot always be provided. The fact that the family moves approximately every three years and that the medical officers move every three years; means lack of continuity of surveillance which is a disadvantage, and documents often do not accompany the child on transfer: The housing available at overseas stations is frequently not enough for all the families wanting it, so that some families will always be in privately acquired accommodationpossibly far from the rest of the service community. There is often no basic county of domicile for special services, i.e. for children to be put on waiting lists for special schools, spastic centres and other institution's, when they return to the UK. The family can withstand better the absence or illness of the father, but if mother is ill, the repercussions can be serious. Either the father has to go off duty or else some other arrangement has to be made for the children; this is basically a unit responsibility, but is often shifted onto the medical services. We have very few ancillary services e.g., speech therapists, physiotherapists, child psychologists especially trained for children, althougin we now have two child guidance clinics in BAOR, but it remains to be seen how these function under service conditions.

I would now like to discuss briefly some conditions which are sometimes not well handled in practice. 


\section{Gastro-Enteritis}

This as you know, is closely related to unhygienic habits. Any infant with loose "smelly" stools, should be suspected of having it. An infant can tolerate a certain amount of diarrhoea, but if vomiting is added to this it will very quickly become denydrated. At this early stage the substitution of clear fluids, e.g., Hartmann's solution with glucose or boiled water with one teaspoonful of salt and two teaspoonfuls of sugar or glucose to the pint, for twenty-four hours, will often save the infant getting worse. Most of the cases are due to pathogenic $E$. coli (a few of these are viral), sensitive to neomycin sulphate, therefore this drug is the most effective treatment, (oral dose: $40 \mathrm{mgm} / \mathrm{kg} /$ day). Ideally, you should send a stool or rectal swab to the laboratory before starting treatment.

\section{Acute Bronchiolitis in Infancy}

Every winter there is a seasonal increase in demands for hospital beds for respiratory infections, especially for infants. Acute bronchiolitis due to the respiratory syncytial virus is a particularly distressing condition, and it is often difficult to decide from the G.P's point of view which case of coryza or bronchitis is going to become bronchiolitis. It usually affects fat babies with short necks and an early clue may be a little dry hacking cough and early subcostal recession. Many are anaemic and so cyanosis may not be evident in these fat, wheezy babies fighting for their breath. These infants should be in hospital and nearly all tend to get worse towards evening.

\section{Pyelitis in Childhood}

This is a very common condition and is often missed. It usually starts in the first five years of life. As a result of the meticulous work of Smellie, et al. (1964), and Hodson (1965), it has been shown that there is a frequent vesico-ureteric reflux, that scarring of of the kidneys cccurs leading to the so called " atrophic pyelonephritis" seen in adults, which is the commonest cause of hypertension of renal origin at all ages and of progressive renal failure in young adults. Urinary infection in children should, therefore, be carefully sought for and adequately treated and supervised for long periods.

\section{Epilepsy in Childhood}

Apart from fits secondary to some other cause, there are four main clinically recognizable syndromes:-

\section{Febrile convulsions}

These are age specific, usually under five years, familial, benign and self limiting. The electroencephalogram is normal. Phenobarbitone may be given until the family history shows it is safe to stop.

Infantile spasms

Also called nypsarrinythmia - the blitz-, nich-, und salaam-krampfe of the Germansan apparently normal infant starts to have " salaam fits" before the age of one year. Very numerous attacks daily may occur; the response to anti-convulsants is very poor; corticosteroids or A.C.T.H., usually help. There is a sinister prognosis for mental development. The E.E.G. is chaotic with asynchronous, high amplitude, irregular waves; and in many of these cases gross cerebral abnormality is found at autopsy. 


\section{Central or centre-encephalic epilepsy}

There is a genetic factor here. This group includes most cases of petit mal, many generalized fits and myoclonic types of seizure. The prognosis is good for the frequency of fits and their response to treatment. The E.E.G. shows bilateral synchronous activity originating in the brain stem with spike and wave abnormality in the case of petit mal. Treatment includes phenobarbitone and the phenytoins etc., for grand mal attacks and troxidone and phensuximide for petit mal seizures. There is a special caveat here in certain families, where fits start early (in the first year of life) from sudden death in an attack of status.

Cortical

This type is twice as frequent as central and there is a wide range of types. There is no genetic nor familial feature. These are the patients who have an aura. The fits may be major, Jacksonian or psychomotor, are difficult to control and are often accompanied by disturbances of behaboiur. The E.E.G. shows a focal disorder especially over the temporal lobe. There is probably a focal lesion in all cases, i.e., small asphyxial or haemorraghic scars, or a minor congenital abnormality and further fits seem to worsen these patients probably by leading to more asphyxia or thrombosis which predisposes to more fits. There is a variety of drugs for this type of epilepsy, either alone or in combination e.g., primidone and librium. Note that phenobarbitone alone often makes the behaviour disorder worse.

\section{Accidental Poisoning in Children}

Accidents of all types to children are still too frequent and nearly all are avoidable. I should like to mention a few poisons which are commonly ingested because they have a delayed reaction. Unless you are quite sure how much the child has had, what drug and when, these children should have their stomachs wash $d$ out and $b z$ admitted to hospital.

Salicylates (Aspirin). Here the child may seem perfectly well, but a complicated metabolic disorder develops over the next few hours, a mixture of metabolic acidosis and respiratory alkalosis. This requires careful biochemical assessment and therapy, especially forced alkaline diuresis.

Ferrous sulphate. Nearly always the case is a toddler whose mother has recently had a new baby and been given a supply of fersolate tablets (which look like "smarties") - the mother has usually taken some of these and then put the box on a shelf. Ferrous sulphate is very astringent and the whole stomach may be ulcerated, the liver being severely damaged and death all too frequent. Desferrioxamine (a specific chelating agent) should be given as well as the usual supportive measurts.

Barbiturates. These nearly all lead to drowsiness and marked respiratory depression which supervenes rapidly or slowly. Osmotic diuresis with mannitol is probably the therapy of choice.

Hydrocarbon. Paraffin is all too frequently drunk by children. Controversy exists as to whether to wash out the stomachs of such cases because of the risk of lipoid pneumonia from inhalation of the oil; however, as they can usually be turned upside down while this is being done, this lessens the possibility of inhalation. Lipoid pneumonia when it occurs, usually takes about three days to develop and so a radiograph of the chest should be taken about this time. 


\section{Prescribing for Children}

Now I would like to mention the use of the special prescription (E.C.10.S). This as you know, is used for special drugs prescribed outside hospital practice for service patients. There is, however, another class of substance prescribable on this form-special foods for the use of children suffering from certain diseases requiring specific diets.

Examples of these are:-

Coeliac disease _- gluten free flour. N.B., it is the flour that is prescribable and not made up products i.e., bread and biscuits.

Nephritis with salt retention - low salt milk powder. e.g., Edosol.

Phenylketonuria - phenylalanine free foods e.g., Cymogran, Minofen, Lofenolac.

Galactosaemia - low lactose foods. e.g., Galactomin, Velactin.

Hypercalcaemiá - low calcium milk. è.g., Locasol.

The authority for prescribing these specific foods is clearly set out in the pamphlet by the Joint Committee on the Classification of Propriety Preparations and is emphasised again in the Prescribers Journal. "The Supply of Special Articles of Diet on EC.10."

\section{What can be learnt from the Facies of an Infant}

There are many characteristic facies which are diagnostic, but I would like to mention two conditions which are not so well known outside paediatric practice.

The Potter facies of renal agenesis

These newborn babies do not of course survive, but they are clinically diagnosable shortly after birth, with large low set ears, very marked epicanthic folds, broad space. between the eyes, micrognathia, flattening of the nose and a crease on the chin. Lesser degrees of renal abnormality such as hypoplasia may have somc of these facial features.

Further, it has been sincwn by Taylor (1965), that children with deformed ears and especially associated with hypoplasia of the face on the same side, frequently have a renal abnormality (hypoplasia or malposition) on the same side as the deformed ear. Such children should, therefore have full renal tract investigation.

Idiopathic hypercalcaemia of infants

This is a condition affecting children in the first year. There are two separate types:one due to an excess of vitamin $\mathrm{D}$ which is reversible and the other type not the result of vitamin $\mathrm{D}$ excess, who have a characteristic facies. The features of this condition are anorexia, vomiting, failure to gain, constipation, thirst and polyuria. The urine may contain pus cells and the blood calcium and urea are raised. Dr. Schlesinger (formerly Honorary Consultant in Paediatrics to the Army) amongst others, drew attention to a severe type with hypertension, osteosclerosis, nephrocalcinosis, and to these has been added supravalivar aortic stenosis. Mental development may be retarded.

The facial appearances are an "elf-like" face with very round eyes, large, low set ears, forward pointing nostrils, a long upper lip, and epicanthic folds. All the patients look very much alike.

\section{REFERENCES}

Smellie, J. M., Hodson, C. J., Edwards, D. and Norman, I. C. S. (1964). Brit. med. J. 2, 1222.

Hodson, C. J.'(1965). Proc. roy. Soc. Med. 58, 785.

TAYLOR, W. C. (1965). Canad. med. Ass. J. 93, 107.

POTTER, E. L. (1946). J. Paediat. $29,68$.

H. M. STATIONERY Office. Prescribers Journal. 4, 122. 